\title{
GPS and DGPS as a Challenge for Environmentally-Friendly Agriculture*
}

\author{
Hermann Auernhammer, Thomas Muhr and Markus Demmel \\ (Freising-Weihenstephan)
}

\begin{abstract}
For farming in the future, positional information is of particular importance. Out of a multitude of positioning systems, GPS/DGPs is the most suitable one. This system does not require any additional infrastructure and at the same time guarantees complete coverage of all tilled surfaces. The major application of positioning with GPS/DGPS is to be seen in the area of local information and documentation. By generating both planning and process data, it facilitates the operation and control of work processes (organic and mineral fertilization, plant protection). In the end, positioning leads to navigation, which, in the case of single vehicles and vehicle pools, will in turn provide completely new possibilities for development and application. For the first time, vehicles without drivers are conceivable. Thus, the completion of any kind of work on schedule, without time limitations, would become possible with the least possible stress for soil and environment.
\end{abstract}

I. INTRODUCTION. The economies of higher developed countries are marked by industrialization and an increasing range of services offered. As a contrast, the share of the population working in the agricultural sector is decreasing steadily. Remaining agricultural operations try to maintain their competitiveness by increasing the size of operational units, with growing levels of mechanization and increases in yield. In the past, this tended to result in site-related environmental stress on the one hand and unused resources on the other. Despite, or perhaps because of, these immense efforts, the public image of both agriculture and environment has suffered in more than one respect.

2. environmentally FRIENDly Means 'LOCAL'. Plant production always depends on the conditions at the site; that is, for the most part, on the soil and its local characteristics such as type, nutrient supply and water-bearing qualities. Environmentally-oriented production aims at integrating the existing, natural factors so as not to induce any lasting changes. In the case of nutrient supply this means, for example, fertilization based on nutrient uptake. The quantity of nutrients supplied equals the amount actually taken up and processed by the plants.

In the past, it was the individual farmer himself who took into account the above-mentioned factors. As long as the plots were of manageable size he was likely to be familiar with every square foot of his farm and fields. His daily routine yielded constant feedback to which he could react with his expertise. However, with increasing plot size and the employment of temporary workers, local information was lost at an increasing rate. Farmers were left with having to look at the harvest as a single unit, although, as the acreage to be harvested increased in size, so did the variability within the respective harvests. These disadvantages

* Updated reprint of the paper presented at the EURNAV 94 Conference. 
can only be eliminated through sensing soil and yield in connection with reliable and exact positioning. Thus, position-related soil cultivation with a small-scale orientation would combine the advantages of small farming operations (ecological aspects) with large-scale, cost-efficient cultivation methods (economic aspects).

For agricultural vehicles, a variety of positioning systems is currently available (Figure I). All systems have inherent advantages and disadvantages (Table I).

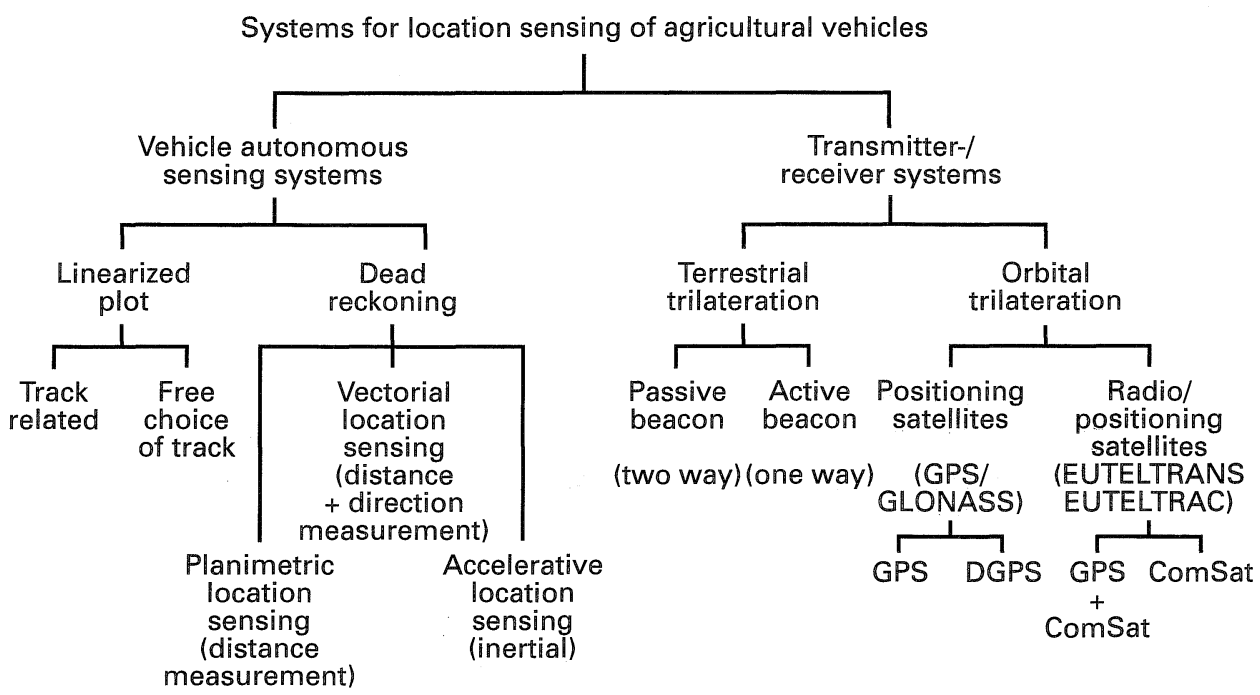

Fig. I. Systematic representation of positioning of agricultural vehicles

However, only the satellite positioning system GPS or DGPS meets the demands for universal application. It is the only system that allows operation $24 \mathrm{hrs} /$ day, independently of weather conditions, without additional infrastructure and at an individual or extra-operational level. Possibilities of application for GPS/DGPS in agriculture can be divided into two fields: location sensing and navigation (Figure 2).

3. LOCATION SENSING. Again two areas of GPS/DGPS usage are given:

3.I. LOCAL DATA ACQUISITION. Improved management techniques need more and better data or information. Location sensing yields geographical information. Location sensing results in geo-referencing of obtained information (geo-coding) and therefore supplies all information with its corresponding spatial co-ordinates. The following factors are important in this respect.

3.I.I. Application monitoring. The focus here is information about the application of fertilizer, manure and chemicals per plot or part plot. At the time of application, the quantity of fertilizer supplied is a key variable for the desired balance of supply and uptake. On the other hand, the pesticides used are more a quality criterion for the buyer of food.

Additionally, there is the use of an increasing amount of biological refuse from households and industry. For this waste, complete and comprehensive documentation should now be required; that is, from its place of origin to its distribution on the fields, as far as location, date and amounts are concerned. In 


\begin{tabular}{|c|c|c|c|c|}
\hline & \multicolumn{2}{|c|}{ Vehicle autonomous sensing systems } & \multicolumn{2}{|c|}{ Transmitter-/receiver systems } \\
\hline & Linearized plot & Dead reckoning & Terrestrial trilateration & Orbital trilateration \\
\hline Advantage & $\begin{aligned} \rightarrow & \text { only I sensor needed } \\
\rightarrow & \text { error-correction possible at } \\
& \text { every tramline end } \\
\rightarrow & \text { no sensor-infrastructure } \\
& \text { needed }\end{aligned}$ & $\begin{array}{l}\rightarrow \text { no sensor-infrastructure } \\
\text { needed }\end{array}$ & $\begin{aligned} \rightarrow & \text { high precision } \\
\rightarrow & \text { no farm external actions } \\
& \text { necessary }\end{aligned}$ & $\begin{aligned} \rightarrow & \text { worldwide high } \\
& \text { development activity } \\
\rightarrow & \text { universal use for high } \\
& \text { production numbers and low } \\
\text { prices } & \text { position, time and velocity } \\
& \text { available all the time } \\
\rightarrow & \text { infrastructure built and } \\
& \text { maintained by the operator }\end{aligned}$ \\
\hline Disadvantage & $\begin{array}{l}\rightarrow \text { work only possible if starting } \\
\text { at the dead point } \\
\rightarrow \text { varying tramline distances } \\
\text { cause errors } \\
\rightarrow \text { after a break it is necessary } \\
\text { to follow the already worked } \\
\text { way starting at the field dead } \\
\text { point }\end{array}$ & $\begin{array}{l}\rightarrow \text { known starting point (dead } \\
\text { point) needed } \\
\rightarrow \text { errors by poor traction (drift } \\
\text { of vehicles) } \\
\rightarrow \text { errors remain in the system } \\
\text { and sum up till the system is } \\
\text { recalibrated at the starting } \\
\text { point }\end{array}$ & $\begin{aligned} \rightarrow & \text { cost for installation and } \\
& \text { maintenance } \\
\rightarrow & \text { flat area needed } \\
\rightarrow & \text { increasing errors close to } \\
& \text { beacon, may be reduced by } 3 \\
& \text { or more beacons (higher } \\
& \text { costs) }\end{aligned}$ & $\begin{aligned} \rightarrow & \text { depending on operator } \\
\rightarrow & \text { standard signals with } \pm \text { roo } \mathrm{m} \\
& \text { errors ( } 95 \% \text { of all deviations) } \\
\rightarrow & \text { for higher accuracy use of } \\
& \text { DGPS with base station } \\
& \text { necessary, requires online- } \\
& \text { radio-connection, higher } \\
& \text { costs }\end{aligned}$ \\
\hline Error & $\begin{array}{l}\text { working width }(x) \pm 3-\text { I } 2 \% \\
\text { way length }(y) \pm \mathrm{I}-3 \% \text { by } \\
\text { error-correction on tramline } \\
\text { end) }\end{array}$ & $\begin{array}{l}\geqslant \pm \text { I nautical mile } / 8 \mathrm{~h} \\
\quad(\geqslant \pm 6.4 \mathrm{~cm} / \mathrm{s}) \\
=\text { with } 7 \mathrm{~km} / \mathrm{h} \geqslant \pm 3 \%\end{array}$ & $\pm 20 \mathrm{~cm}- \pm \infty$ & $\begin{array}{l} \pm \text { IO० } \mathrm{m} \text { with GPS } \\
\pm \mathrm{I}-2 \mathrm{M} \text { WITH DGPS }\end{array}$ \\
\hline Assessment & $\begin{array}{l}\text { suitable for carefully working } \\
\text { farmers for the on-farm use in } \\
\text { fields with row-crops or } \\
\text { tramlines }\end{array}$ & $\begin{array}{l}\text { as a single system not } \\
\text { satisfactory for agricultural } \\
\text { use }\end{array}$ & $\begin{array}{l}\text { as an onfarm system it is } \\
\text { satisfactory on large and flat } \\
\text { areas }\end{array}$ & $\begin{array}{l}\text { nearly unlimited useability with } \\
\text { excellent possibilities for } \\
\text { contractor and machinery-ring } \\
\text { use and hilly landscapes (using } \\
\text { DGPS) }\end{array}$ \\
\hline
\end{tabular}




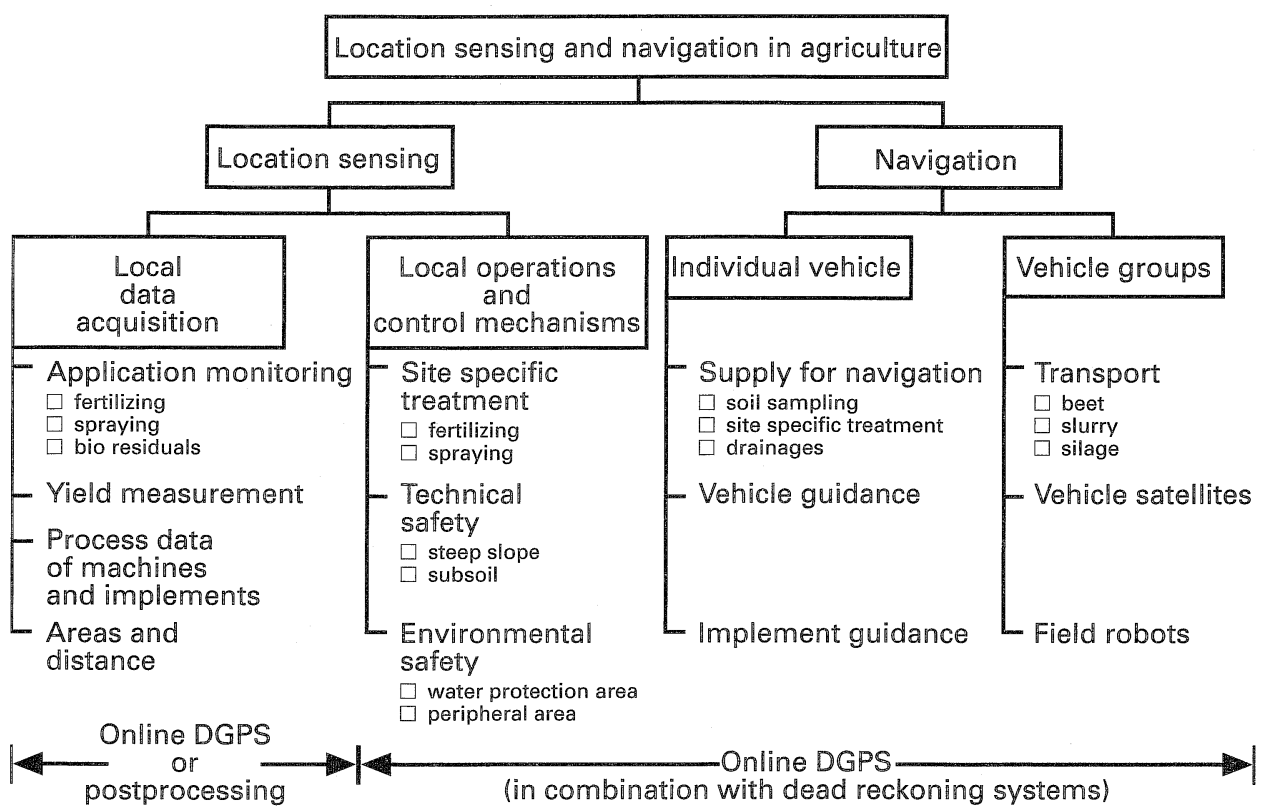

Fig. 2. Applications for location sensing and navigation in agriculture
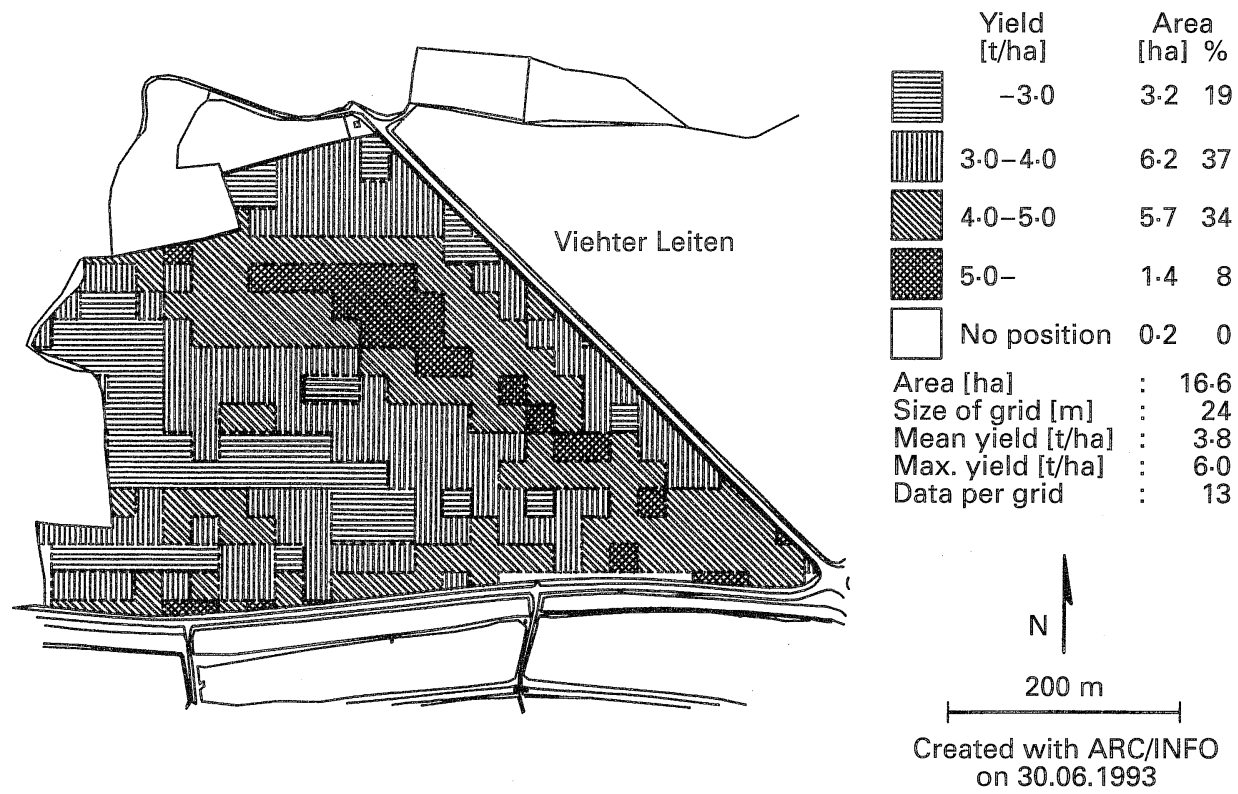

Fig. 3. Yield Map Scheyern 'Flachfeld' 1992. (Spring-barley; MF-DGPS; yield detection with DATAVISION-FLOWCONTROL)

light of a constantly increasing consciousness about environmental issues among the population, this is the only way to ensure future production on surfaces to which such waste materials are currently applied.

3.I.2. Yield Measurement. It can be assumed, without danger of exaggeration, 
that most grain-producing operations only have an approximate idea about the exact yields of their fields. In the production chain 'bulk goods' of today, where the unit 'bag' has been eliminated, traditional ways of estimating are no longer possible. However, scales for weighing yields on the farms themselves are still the exception. Yield measurement in combines and silage harvesting machines could close this information gap.

Also, locally-measured yield reflects nutrient extraction. Therefore it is a very important variable in the desirable balance of supply and uptake. Today, local yield measurement is feasible with combine harvesters and thus available on the market on a continuous basis (Figure 3). Solutions for yield measurement for sugar beet, silage, corn and potatoes are still to be developed.

3.I.3. Process Data of Machines and Implements. Almost all agricultural operations use their machines far too little. The machine times or areas processed are often unknown. Purchasing decisions are frequently made on impulse rather than according to real need. This situation is also trus for operations with improved management techniques and existing electronic databanks for harvest data. Many of these operations cease recording the necessary data after a rather short time because the required data is either inaccurate or not available at all.

Automatized data collection by means of already available sensor devices in tractor and implements is therefore, in conjunction with positioning, the basis for a potential decrease in operational costs (Table 2).

TABle 2. Automatic WORK TIME ACQUisition WITH DGPS AND ADDITIONAL SENSORS

\begin{tabular}{|c|c|c|c|c|c|c|}
\hline \multirow[b]{2}{*}{ Plot } & \multirow[b]{2}{*}{$\begin{array}{c}\text { Area } \\
\text { ha }\end{array}$} & \multirow[b]{2}{*}{$\begin{array}{l}\text { Total time } \\
\text { hour }: \min \end{array}$} & \multicolumn{4}{|c|}{ Relative part of total time } \\
\hline & & & Threshing & $\begin{array}{c}\text { Bin } \\
\text { emptying }\end{array}$ & Idle drive & $\begin{array}{l}\text { Stand still } \\
\text { time }\end{array}$ \\
\hline Kehrfeld & $25 \cdot 5$ & $9: 56$ & 63.05 & $6 \cdot 33$ & I 3.00 & $17 \cdot 30$ \\
\hline Flachfeld & 16.6 & $6: 54$ & 72.69 & $6 \cdot 10$ & I $3 \cdot 7$ I & $7 \cdot 49$ \\
\hline Unteres Hohlfeld & $9 \cdot 9$ & $3: 20$ & $62 \cdot 44$ & $7 \cdot 5^{8}$ & $22 \cdot 07$ & $7 \cdot 83$ \\
\hline Eulenwies & $5 \cdot 3$ & $2: 14$ & $67 \cdot 37$ & $6 \cdot 62$ & $19 \cdot 37$ & $6 \cdot 5^{8}$ \\
\hline Unteres Geiswegfeld & $3 \cdot 4$ & $\mathrm{I}: 25$ & $70 \cdot 51$ & $7 \cdot 27$ & 16.66 & $5 \cdot 57$ \\
\hline Oberes Geiswegfeld & $3 \cdot 3$ & $1: 33$ & $68 \cdot 76$ & $7 \cdot 5^{8}$ & $2 I \cdot 60$ & $2 \cdot 05$ \\
\hline Heubruch & $3 \cdot I$ & $1: 30$ & $71 \cdot 08$ & 6.09 & $16 \cdot 84$ & $5 \cdot 70$ \\
\hline Hopfengarten & $2 \cdot I$ & $\mathrm{I}: 02$ & $65 \cdot 96$ & 470 & $25 \cdot 04$ & $4 \cdot 29$ \\
\hline $\begin{array}{l}\text { Mean (without Kehrfeld } \\
\text { and Unteres Hohlfeld) }\end{array}$ & & & 69.40 & $6 \cdot 37$ & $18 \cdot 87$ & $5 \cdot 28$ \\
\hline
\end{tabular}

3.I.4. Areas and Distances. Every type of work connected with positioning results in surface specification by means of the so-called 'plot envelope'. Movements in the field can be seen as actual distances travelled. This, in turn, provides direct production data in the form of the cutting widths actually used at the harvest as well as in distribution processes and soil cultivation (Table 3 ). With regard to potential extra-operational use of vehicles, these are conditions for effective management and staff evaluation; that is, for effective control of output and resulting costs. 
Table 3. Calculated threshing distances using Dgps for positioning detection. SCHEYERN HARVEST, I 992

Calculated parameters from the threshing distance

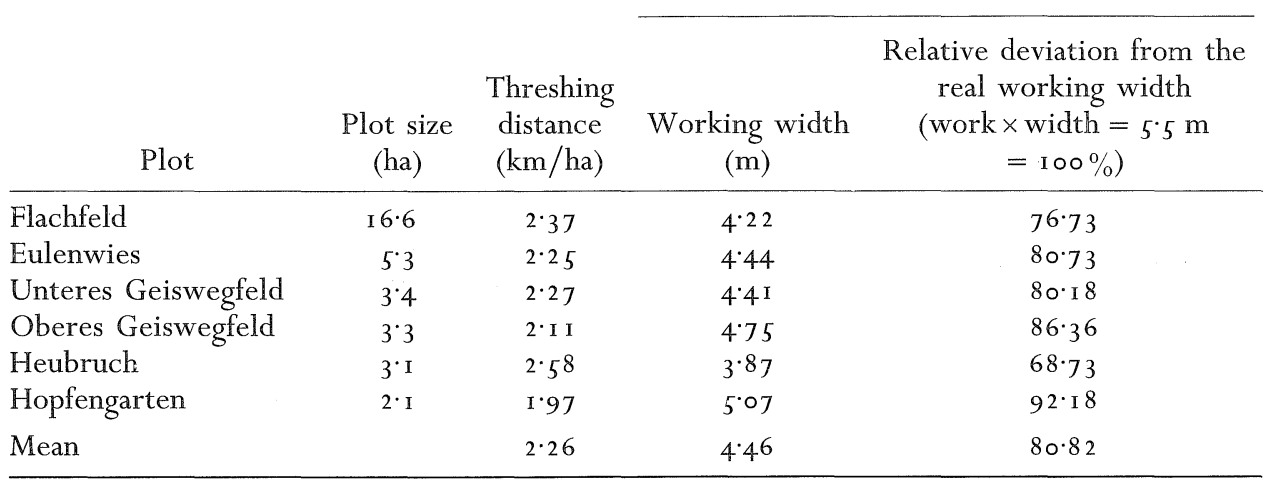

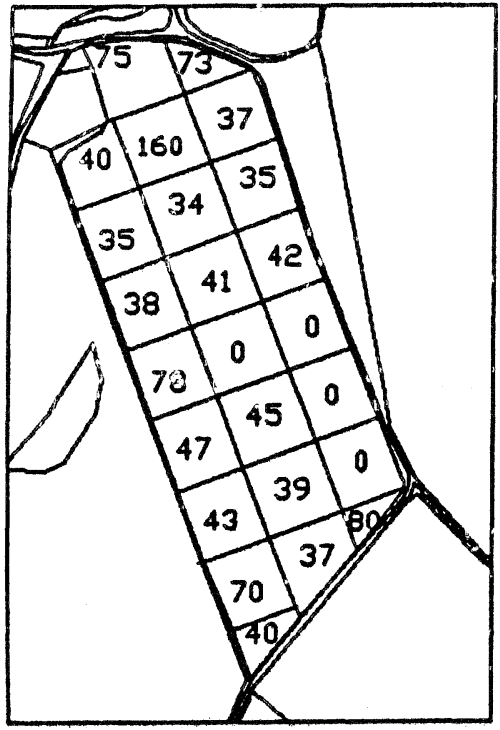

Fig. 4. Map of $\mathrm{P}_{2} \mathrm{O}_{5}$ fertilization rates $(\mathrm{kg} / \mathrm{ha}$ ) based on soil type, georeferenced soil analysis and local yield mapping. (Map generated in cooperation with J. K. Schueller, University of Florida)

3.2. LOCAL OPERATION AND CONTROL MECHANisms. Geo-referenced information means information available at a respective position. Thus, if positioning is available at the vehicle, operational controls may be accessed. A number of intermediate stages are conceivable, starting with a display for the driver only and leading to almost totally automatized processes.

3.2.1. Site-Specific Treatment. Positioning data available during the working process provides the possibility for incorporating different requirements of 


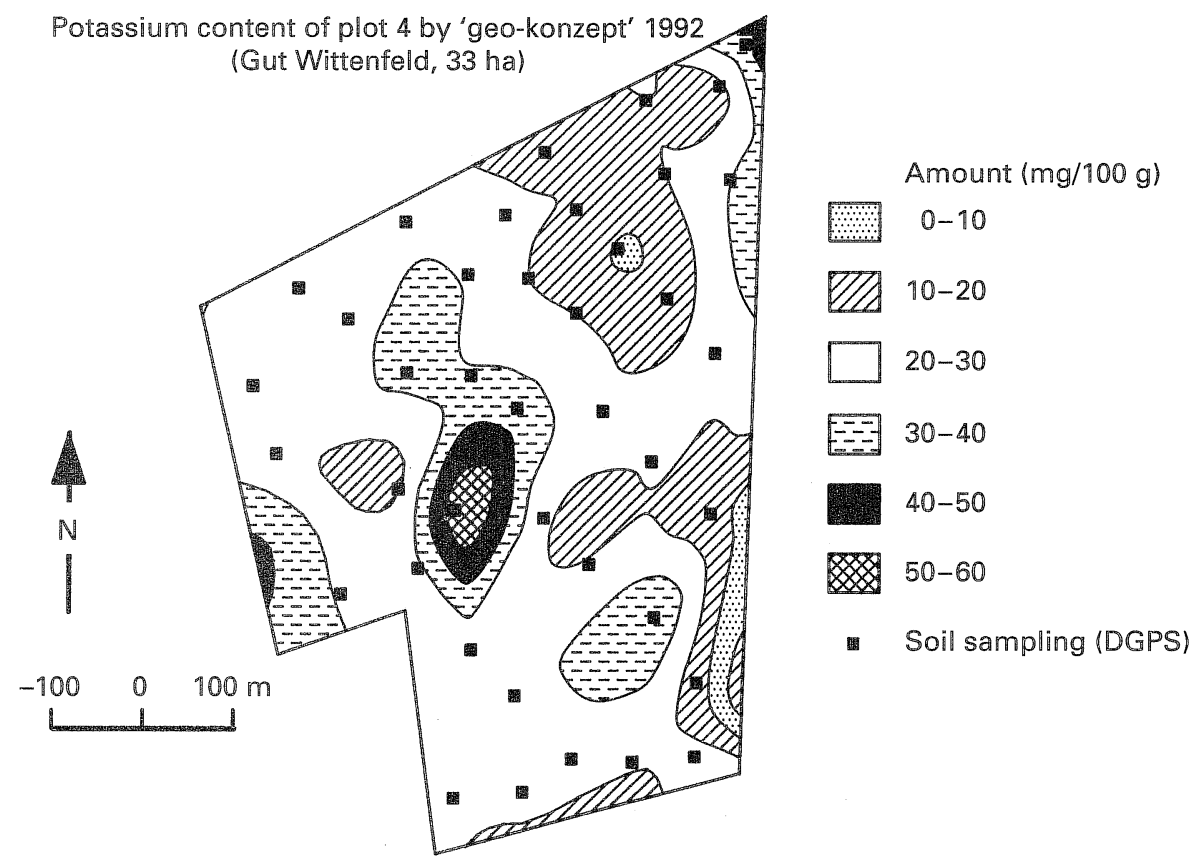

Fig. 5. Graduated potassium supply with respect to geo-referenced soil sampling by geo-konzept, I 993

fertilizer and plant protective agents via manual adjustment or control circuits (Figure 4). With GPS/DGPS, these activities may be carried out in a reliable and cost-efficient way and, for the first time, also on an intra-operational basis.

3.2.2. Technical Safety. Positioning data available during the working process also opens up completely new possibilities concerning the reliability of implement operation and safety of staff in the case of 'local dangers'. Moist spots on the field may, for example, be pointed out (to avoid stuck vehicles) as well as crucial gradients that may pose a problem for certain tractor-implement combinations (to avoid turn-overs). The advantages are obvious: additional, unproductive use of time or possible damages to the technology may be avoided. Reduced safety requirements for staff are also conceivable.

3.2.3. Environmental Safety. GPS/DGPs helps to avoid inadvertent or careless soil treatment within protected surfaces or areas. Among these are areas governed by special water protection regulations and peripheral area projects, precious biotopes within greater agricultural areas and spaces marked for animal and species conservation. For the first time, active resource protection could be effected independently at the planning stage and then documented during operation. Since these measures contribute to a general improvement in the environment, they are of topmost priority.

4. Navigational ReQuirements and possibilities. Finally, the target-oriented aspect of positioning and navigation results in new and promising fields of application. In this respect, two areas are important for agricultural use. 
4. I. INDIVIDUAL VEHICLES. Currently, navigation of individual vehicles is already being made practical use of in the form of navigational aids. The focus is on the systematic collection of soil samples (Figure 5).

This system incorporates the following steps:

(i) Marking off the area to be used for testing with DGPS and recording of the plot envelope.

(ii) Marking off potentially 'excluded areas' (woods, biotopes etc.)

(iii) Calculation of total testing area.

(iv) Determination of required sample figure.

(v) Identification and distribution within the available area of points where samples are to be collected.

(vi) Approaching chosen points with the aid of DGPS.

(vii) Collecting of samples and recording of the corresponding co-ordinates.

This process, with the help of geostatistics, yields surface-adjusted charts of available nutrients, thus providing the possibility of a partial, harvest-oriented requirement analysis and appropriate fertilization (Figure 6).

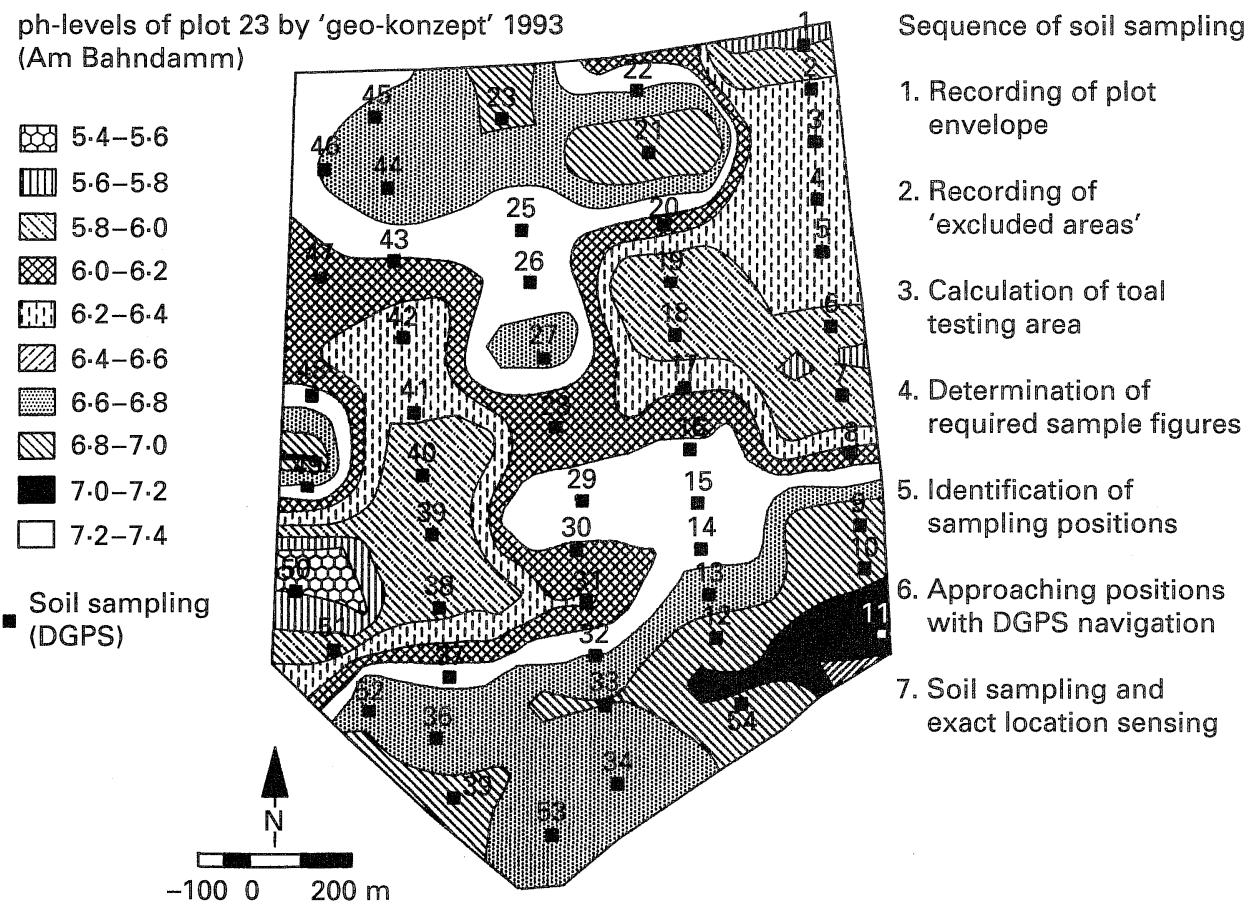

Fig. 6. Map of pH-levels on plot 23 (Am Bahndamm) established after DGPS-based soil sampling by geo-konzept, 1993

Navigational help available from DGPS could also serve to locate geo-referenced supply and disposal devices in the soil (drainage, cables, irrigation ducts for example). Moreover, previously defined borders for partial plots may be accessed more easily. 
Further features serve to make tractor or vehicle navigation easier for the driver. With respect to mechanical weeding devices this will lead to measures that allow a more careful handling of resources. For this, however, additional investment in a dead reckoning system is required, which in turn would enhance the precision of vehicle and implement operation.

5.2. VEHICLE POOLS. As far as transport is concerned, time and volume are the most important factors. Both lead to significant environmental problems, unless appropriate dates and shortest distances are used. For contractor and machinery-ring-operated transports, this can only be achieved with the help of navigational systems. In the agricultural sector, the transport of sugar-beets is of top priority. Transports from field to plant, centrally organized by the sugar industry and at the same time taking into account appropriate harvesting dates and operational units of different sizes, are a typical problem of vehicle pool management (fleet management). Determining suitable points of departure is a great navigational challenge, since accurate navigation in the range of $10-20 \mathrm{~m}$ is required. Imperfect navigation leads to significant losses of time or undesirable over-extension of badly built-up roads. It can also lead to total loss of transport units for a longer period of time.

Similar problems are to be found in the case of contractor and machinery-ringoperated liquid manure distribution and extra-operational silage harvesting processes, where large combines are concerned.

In the future, navigational management of vehicle pools will lead to discussions about vehicle satellites and driverless field robots. This technology should, however, only receive further attention when positioning has provided an electronic solution to all other above-mentioned tasks and current production conditions have consequently been changed in a way that allows a more careful handling of resources. Then the first useful attempts are conceivable at grain sowing and harvesting. For example, at sowing, a manned sowing vehicle (requiring detailed manual operation) would operate in conjunction with unmanned vehicles for seedbed preparation on always exactly coordinated surfaces (Figure 7).

On the other hand, at harvest, a manned head combine would be followed by one or more unmanned satellite combines, since the latter have to perform processes determined by the preceding one.

It is entirely possible to imagine further developments if the driver of the vehicle is to be eliminated completely. The machines then would not need any further increases in size. Optimized units could, with less soil pressure and ideal use of traction force, work independently on previously marked areas. In visions of the future, these 'herds of robots' would result in team-like conditions, bringing agricultural operations to a point they once were at - at the time of plough-boys, handmaids and domestics; that is, to centrally managed operations with a flock of 'servants'.

6. ACKNOWLEDGEMENTS. The scientific activities of the research network Forschungsverbund Agrarökosysteme München (FAM) are financially supported by the Federal Ministry of Research and Technology (BMFT 0339370). Rent and operating of the experimental farm in Scheyern are paid for by the Bavarian State 


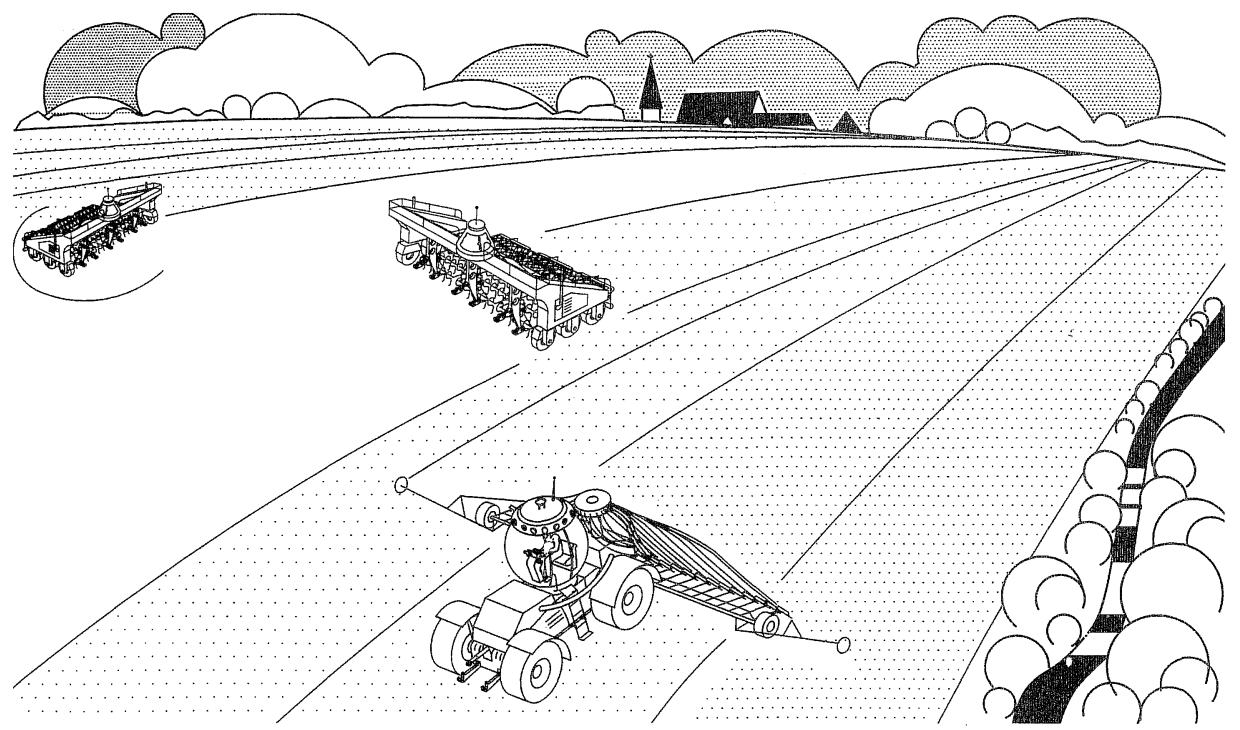

Fig. 7. 'Tractor-fiction': manned sowing tractor with driverless satellites for seedbed preparation

Ministry for Education and Culture, Science and Art. The research project for yield measurements in round balers is financed by the Bundesministerium für Ernährung, Landwirtschaft und Forsten. The research project examining positioning systems for agricultural use was financed by the Bavarian State Ministry for Agriculture and Forestry.

\section{REFEREN CES}

Auernhammer, H. (ed.) (1994). GPS in agriculture. Computers and Electronics in Agriculture, I I, I-2.

Auernhammer, H., Demmel, M., Muhr, T., Rottmeier, J. and Wild, K. (1994). Site-specific yield measurement in combines and forage harvesting machines. In AGENG MILANO '94. Proceedings of the International Conference on Agricultural Engineering, Milano, 29-I September I 994, part 2, pp. 698/699, report no. 94-d-1 39 .

Auernhammer, H., Demmel, M. and Muhr, T. (1994). GPS and DGPS as a challenge for environment-friendly agriculture. Proceedings of the 3rd International Conference on Land Vehicle Navigation, Dresden. Deutsche Gesellschaft für Ortung und Navigation e.v., The German Institute of Navigation, Düsseldorf.

Auernhammer, H., Demmel, M., Muhr, T., Rottmeier, J. and Wild, K. (1993). Yield measurement on combine harvesters. ASAE paper no. 93-1506. St Joseph.

Auernhammer, H., Demmel, M., Muhr, T., Rottmeier, J. and Perger, P. (1 993). Ortung und Ertragsermittlung in den Erntejahren 199 I und i 992 . Zeitschrift für Agrarinformatik, I (I), 26-29.

Auernhammer, H. and Demmel, M. (1993). Lokale Ertragsermittlung beim Mähdrusch. Landtechnik, 48 (6), 3 I 5-3 9 .

Auernhammer, H. and Muhr, T. (199I). GPS in a basic role for environment protection in agriculture. Proceedings of the 1991 Symposium - Automated Agriculture in the 21 st Century, paper no. I I-91, pp. 494-502. ASAE Publications, St Joseph.

Auernhammer, H. and Muhr, T. (I99I). The use of GPs in agriculture for yield mapping and tractor implement guidance. Proceedings of DGPS'91 - First International Symposium on Real-Time 
Applications of the Global Positioning System, vol. II, pp. 455-465. Deutsche Gesellschaft für Ortung und Navigation e.v., The German Institute of Navigation, Düsseldorf.

Auernhammer, H., Demmel, M., Rottmeier J. and Muhr, T. (I99 I). Future developments for fertilizing in Germany. ASAE paper no. 91-1040. St Joseph.

MacLeod, F. (1991). Agricultural vehicle positioning and its integration with a large-scale land information system. This Journal, 44, 30.

Palmer, R. J. (1989). Precise navigation, guidance and control services within the agricultural community. This Journal, 42, I.

Rober, P. C., Rust, R. H. and Larson, W. E. (1992). Soil-specific Crop Management. American Society of Agronomy Inc., Madison, Wisconsin.

Schnug, E., Haneklaus, S. and Lamp, J. (I 990). Economic and ecological optimization of farm chemical application by 'computer aided farming (CAF)'. Technical abstracts and poster abstracts in International Conference on Agricultural Engineering ( $\left.A G E N G^{\prime} 90\right)$, pp. I61-162. Berlin, VDIAGR/MEG.

Schueller, J. K. (1992). A review and integrating analysis of spatially-variable control of crop production. Fertilizer Research, 33, I-34.

Schueller, J. K. et al. (1987). Determination of spatially variability yield maps. ASAE paper no. 87-1 533. St Joseph.

Searcy, S. W., Schueller, J. K., Bae, H. Y. and Stout, B. A. (1990). Measurement of field location using microwave frequency triangulation. Computers and Electronics in Agriculture, 4, 209-223.

Stafford, J. V. and Miller, P. C. H. (1993). Spatially-selective application of herbicide to cereal crops. Computers and Electronics in Agriculture, 9, 2 1 7-229.

Stafford, J. V., Ambler, B. and Smith, M. P. (I99I). Sensing and mapping grain yield variation. Proceedings of the 1991 Symposium - Automated Agriculture in the 21 st Century, paper no. I I-9I, pp. 356-366. ASAE Publications, St Joseph.

Vansichen, R. and De Baerdemaeker, J. (I991). Continuous wheat yield measurement on a combine. Proceedings of the 1991 Symposium - Automated Agriculture in the 21st Century, paper no. I I-9I, pp. 346-355. ASAE Publications, St Joseph.

VDI (Coordinator, H. Auernhammer) (I992). Ortung und Navigation landwirtschaftlicher Fahrzeuge. VDI-Gesellschaft Agrartechnik (VDI-AGR), I 4. Düsseldorf.

\section{KEY WORDS}

I. Land navigation. 2. Agriculture. 